\title{
Retraction Note to: Environmental PM2.5 concentration and optimization of college students' mental health index based on variance parameter model
}

\author{
Yuhang Wang ${ }^{1} \cdot$ Qianying Luo $^{1}$
}

Published online: 3 November 2021

(c) Saudi Society for Geosciences 2021

Retraction Note to: Arabian Journal of Geosciences (2021) 14: 1778

https://doi.org/10.1007/s12517-021-08074-3

The Editor-in-Chief and the Publisher have retracted this article because the content of this article is nonsensical. The peer review process was not carried out in accordance with the Publisher's peer review policy. The authors have not responded to correspondence regarding this retraction.

The original article can be found online at https://doi.org/10.1007/ s12517-021-08074-3.

Qianying Luo

lqy516@126.com

1 College of Marxism, Zhejiang University of Finance \& Economics, Hangzhou 310018, Zhejiang, China 